\title{
Totality of evidence needed for nutrition recommendations
}

\section{Arne Astrup and Jennie Brand-Miller}

We thank Pi-Sunyer and colleagues (We stand by our guidelines. Nat. Rev. Endocrinol. 10, doi: $10.038 /$ nrendo.2013.272-c1 $)^{1}$ for responding to our criticism of the 2013 guidelines for the management of overweight and obesity that were produced by these authors on behalf of the American Heart Association (AHA), the American College of Cardiology (ACC) and The Obesity Society (TOS) (Have new guidelines overlooked the role of diet composition? Nat. Rev. Endocrinol. 10, 132-133; 2014). ${ }^{2}$ Our disagreement is about how to assess the evidence evaluating the importance of diet composition for weight control. Whereas Pi-Sunyer et al. stand by their use of the Institute of Medicine (IOM) methodology-which recognizes only long-term randomized controlled trials (RCTs) with high retention rates as evidence for consideration-we maintain that this approach is far too narrow for nutrition studies. If the IOM criteria were the only measure of the validity of scientific evidence, we would need RCTs to assess the efficacy and safety of the parachute before its use could be endorsed.

We think it necessary to distinguish between the evidence required to establish effects of diet composition on body weight and that required for synthetic pharmaceutical compounds. To establish a causal link between diet composition and obesity, one first needs to include evidence from animal, experimental, mechanistic, observational and interventional studies, and look at the totality of evidence, as recommended by the FDA. ${ }^{3}$ The approach used by Pi-Sunyer et al. might to some extent be acceptable for drug trials that aim to assess the efficacy and safety of new molecules; however, using the same methodology in research that examines the role of naturally occurring foods and/or nutrients essentially eliminates the majority of all scientific studies in the area.

Had the same criteria for evidence been applied to the assessment of the importance of industrially produced trans fats for cardiovascular disease, not a single study would have been identified. Consequently, Denmark would not have banned trans fats and would not have experienced the largest reduction in ischaemic heart disease in Europe (77\%) since $1990 .^{4}$

Pi-Sunyer et al. dismiss our examples of meta-analyses of RCTs (comprising 110 studies in total) that show benefits of slightly reducing carbohydrate and increasing protein for body weight control, as "prospective, observational studies with self-reported outcomes," when in fact there were substantial positive effects on body weight, body fat, preservation of fat-free mass and important cardiometabolic risk factors. ${ }^{5-7}$ Moreover, recently conducted meta-analyses of longterm trials show lasting effects after the cessation of active intervention. ${ }^{8,9}$ Another meta-analysis has demonstrated benefits of a low glycaemic index diet among individuals with obesity. ${ }^{10}$

We should also distinguish between high trial 'retention' and high 'dietary adherence'. High retention essentially means that participants just have to attend the control visits; consequently, very high retention rates can be achieved by, for example, cash rewards after completion of the trial. By contrast, high adherence (or compliance) with diet composition can be achieved by techniques such as careful instruction by dieticians, cookery classes and provision of all foods free of charge. In the POUNDS LOST trial, an $80 \%$ retention rate was reported after 2 years. ${ }^{11}$ However, compliance with diet composition was poor because nitrogen excretion among individuals assigned to the normal-protein and high protein diet groups was identical, indicating that protein intake did not differ between these two groups. By contrast, in the Diogenes trial, participants' urinary nitrogen excretion showed that they had adhered to the allocated protein intakes, and better weight control was achieved in the high protein groups than in the low protein groups. ${ }^{12}$ Moreover, the drop-out rate was much lower in the groups with enhanced weight control (high-protein, low glycaemic index).

We agree with Pi-Sunyer and colleagues that there is no magic bullet in diet composition for weight control. Nonetheless, the effects of 1-2 kg weight regain over a period of 6-12 months can be enough to distinguish between weight stability and marked weight gain over time.

Department of Nutrition, Exercise and Sports, Faculty of Science, University of Copenhagen, Nørre Alle 51, DK-2200 Copenhagen N,

Denmark (A.A.). Charles Perkins Centre and School of Molecular Bioscience, University of Sydney, Biochemistry Building, G08, Sydney 2006, NSW, Australia (J.B.-M.).

Correspondence to: A.A.

ast@nexs.ku.dk

\section{Acknowledgements}

A.A. is supported by the OPUS Center, which is funded by a grant from the Nordea Foundation.

\section{Competing interests}

A.A. has conducted research funded by meat and dairy organizations, and currently acts as consultant for the following companies with interests in the food marketing sector: Gerson Lehrman Group (ad hoc consultant for clients); Global Dairy Platform; Jenny Craig; McCain Foods; and McDonald's. J.B.-M. is the co-author of books about the glycemic index (Gl) of foods, manages a Gl testing service at the University of Sydney, and is the President of the Glycemic Index Foundation, a not-for-profit health promotion charity that educates consumers and health professionals about the benefits of a healthy low Gl diet.

1. Pi-Sunyer, X. et al. We stand by our guidelines. Nat. Rev. Endocrinol. 10, http://dx.doi.org/ 10.1038/nrendo.2013.271-c1.

2. Astrup, A. \& Brand-Miller, J. Have new guidelines overlooked the role of diet composition? Nat. Rev. Endocrinol. 10, 132-133 (2014).

3. FDA. Guidance for industry: evidence-based review system for the scientific evaluation of health claims -final [online], FDA.gov http:// www.fda.gov/Food/GuidanceRegulation/ GuidanceDocumentsRegulatorylnformation/ LabelingNutrition/ucm073332.htm (2009).

4. Nichols, M., Townsend, N., Scarborough, P. \& Rayner, M. Trends in age-specific coronary heart disease mortality in the European Union over three decades: 1980-2009. Eur. Heart J. 34, 3017-3027 (2013).

5. Santos, F. L., Esteves, S. S., da Costa Pereira, A., Yancy, W. S. Jr \& Nunes, P. L. 
Systematic review and meta-analysis of clinical trials of the effects of low carbohydrate diets on cardiovascular risk factors. Obes. Rev. 13, 1048-1066 (2012).

6. Krieger J. W., Sitren, H. S., Daniels, M. J. \& Langham-Henken, B. Effects of variation in protein and carbohydrate intake on body mass and composition during energy restriction: a meta-regression. Am. J. Clin. Nutr. 83, 260-274 (2006).

7. Wycherley, T. P., Moran, L. J., Clifton. P. M. Noakes, M. \& Brinkworth, G. D. Effects of energy-restricted high-protein, low-fat compared with standard-protein, low-fat diets: a meta-analysis of randomized controlled diets. Am. J. Clin. Nutr. 96, 1281-1298 (2012).

8. Clifton, P. M., Condo, D. \& Keogh, J. B. Long term weight maintenance after advice to consume low carbohydrate, higher protein diets-a systematic review and meta-analysis. Nutr. Metab. Cardiovasc. Dis. http://dx.doi.org/ 10.1016/j.numecd.2013.11.006.

9. Astrup, A. \& Geiker, N. R. Efficacy of higher protein diets for long-term weight control. How to assess quality of randomized controlled trials? Nutr. Metab. Cardiovasc. Dis. (in press).
10. Schwingshackl, L. \& Hoffmann, G. Long-term effects of low glycemic index/load vs. high glycemic index/load diets on parameters of obesity and obesity-associated risks: a systematic review and meta-analysis. Nutr. Metab. Cardiovasc. Dis. 23, 699-706 (2013).

11. Sacks, F.M. et al. Comparison of weight-loss diets with different compositions of fat, protein, and carbohydrates. N. Engl. J. Med. 360, 859-873 (2009).

12. Larsen, T. M. et al. Diets with high or low protein content and glycemic index for weightloss maintenance. N. Engl. J. Med. 363 , 2102-2113 (2010). 